\title{
Blockade of glucocorticoid receptors with RU486 attenuates cardiac damage and adipose tissue inflammation in a rat model of metabolic syndrome
}

\author{
Yuuri Takeshita $^{1}$, Shogo Watanabe ${ }^{1}$, Takuya Hattori ${ }^{1}$, Kai Nagasawa ${ }^{1}$, Natsumi Matsuura ${ }^{1}$, Keiji Takahashi ${ }^{1}$, \\ Toyoaki Murohara ${ }^{2}$ and Kohzo Nagata ${ }^{1}$
}

Glucocorticoids are stress hormones that modulate metabolic, inflammatory and cardiovascular processes. We recently characterized DahIS.Z-Lepra/Lepra (DS/obese) rats, derived from a cross between Dahl salt-sensitive (DS) and Zucker rats, as a new animal model of metabolic syndrome (MetS). We have now investigated the effects of glucocorticoid receptor (GR) blockade on cardiac and adipose tissue pathology and gene expression, as well as on glucose metabolism in this model. DS/obese rats were treated with the GR blocker RU486 ( $2 \mathrm{mg} \mathrm{kg}^{-1}$ per day, subcutaneous) for 4 weeks beginning at 9 weeks of age. Age-matched homozygous lean (DahlS.Z-Lepr ${ }^{+} / \mathrm{Lepr}^{+}$, or DS/lean) littermates of DS/obese rats served as controls. Treatment of DS/obese rats with RU486 attenuated left ventricular (LV) fibrosis and diastolic dysfunction, as well as cardiac oxidative stress and inflammation, without affecting hypertension or LV hypertrophy. Administration of RU486 to DS/obese rats also inhibited the

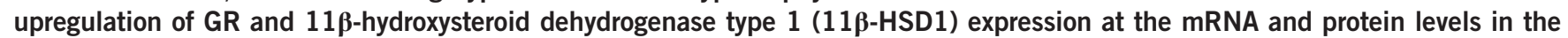

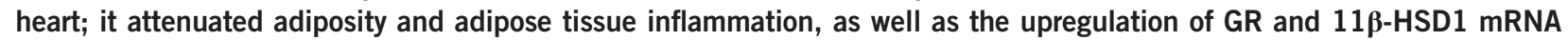
and protein expression in adipose tissue; it ameliorated fasting hyperinsulinemia as well as insulin resistance and glucose intolerance. Our results thus implicate the glucocorticoid-GR axis in the pathophysiology of MetS, and they suggest that GR blockade has therapeutic potential for the treatment of this condition.

Hypertension Research (2015) 38, 741-750; doi:10.1038/hr.2015.77; published online 9 July 2015

Keywords: adipose tissue; cardiac remodeling; glucocorticoid receptor; glucose metabolism; metabolic syndrome

\section{INTRODUCTION}

Glucocorticoids influence a wide variety of physiological functions, including immune and inflammatory responses, stress responses and metabolism. ${ }^{1}$ Both in vivo and in vitro studies have also implicated glucocorticoids in the development of cardiac hypertrophy, a major cause of heart failure. ${ }^{2,3}$ Indeed, circulating glucocorticoid levels are an independent risk factor for cardiovascular disease, ${ }^{4}$ and glucocorticoids can both positively and negatively influence cardiac function through direct effects on cardiomyocytes. ${ }^{5}$ Glucocorticoid excess is a prototypical component of metabolic syndrome (MetS), which is characterized by several closely related disorders including obesity, hyperglycemia, dyslipidemia, hypertension and insulin resistance. ${ }^{6,7}$ $11 \beta$-Hydroxysteroid dehydrogenase type 1 (11 $\beta$-HSD1) is expressed in tissues and cells that are important for metabolic (liver and adipose tissue), inflammatory (macrophages) and cardiovascular (vascular smooth muscle) function. ${ }^{8,9}$ Given that $11 \beta$-HSD1 acts predominantly as a reductase in vivo, converting inactive cortisone into active cortisol, increased expression of $11 \beta$-HSD1 leads to glucocorticoid excess. ${ }^{10}$
The glucocorticoid receptor (GR), which belongs to the nuclear receptor superfamily of ligand-dependent transcription factors, ${ }^{11}$ is expressed in the heart, ${ }^{12,13}$ but the specific role of glucocorticoid signaling in cardiomyocytes is poorly understood. In contrast to the mineralocorticoid receptor (MR), which binds both aldosterone and glucocorticoids with similar affinities, the GR binds glucocorticoids with higher affinity than aldosterone. ${ }^{14}$ The circulating concentration of glucocorticoids is two to three orders of magnitude greater than that of aldosterone, and cardiomyocytes express minimal activity for $11 \beta$-HSD2, which converts glucocorticoids to inactive metabolites. ${ }^{15}$ MRs in the heart are thus thought to be occupied predominantly by glucocorticoids, suggesting that both the GR and MR are potential mediators of glucocorticoid signaling in the heart. ${ }^{5}$ Indeed, we recently showed that exogenous glucocorticoids activate cardiac MRs in adrenalectomized Dahl salt-sensitive (DS) rats. ${ }^{16}$ However, the role of the glucocorticoid-GR system in obesity and MetS has remained unclear.

We recently established a new animal model of MetS, the DahlS. Z-Lepr ${ }^{f a} /$ Lepr $^{\text {fa }}$ (DS/obese) rat, by crossing DS rats with Zucker rats

${ }^{1}$ Department of Pathophysiological Laboratory Sciences, Nagoya University Graduate School of Medicine, Nagoya, Japan and ${ }^{2}$ Department of Cardiology, Nagoya University Graduate School of Medicine, Nagoya, Japan

Correspondence: Dr K Nagata, Department of Pathophysiological Laboratory Sciences, Nagoya University Graduate School of Medicine, 1-1-20 Daikominami, Higashi-ku, Nagoya 461-8673, Japan.

E-mail: nagata@met.nagoya-u.ac.jp

Received 3 December 2014; revised 7 May 2015; accepted 4 June 2015; published online 9 July 2015 
a

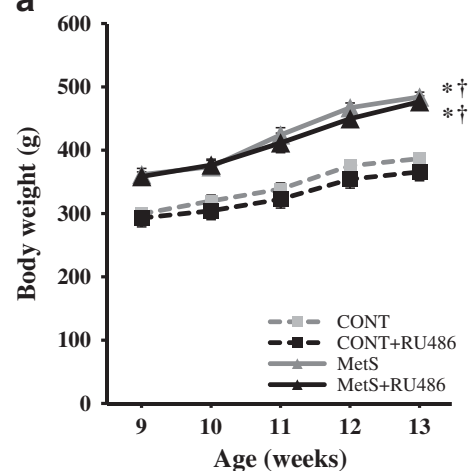

d

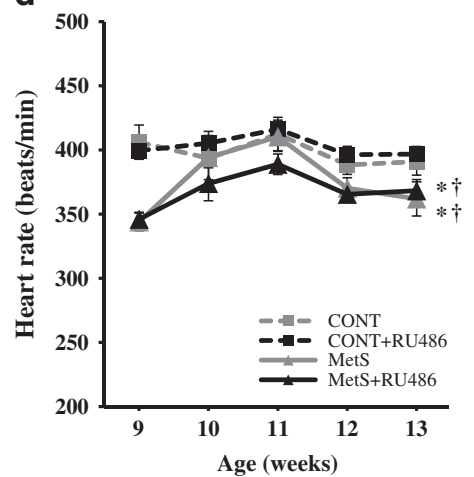

b

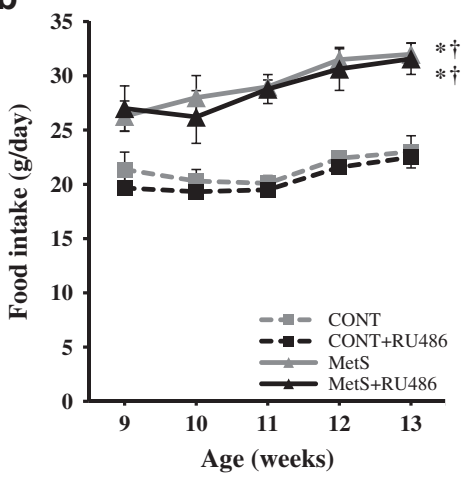

e

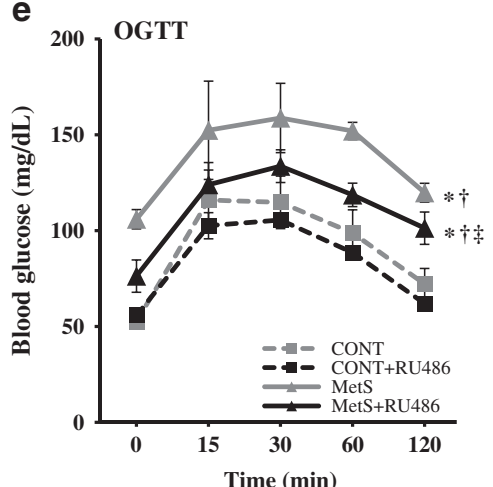

c

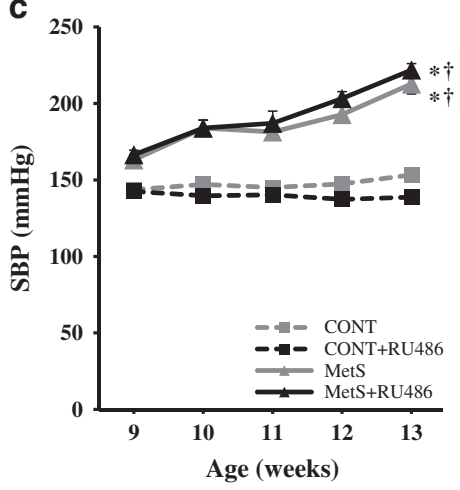

$f$

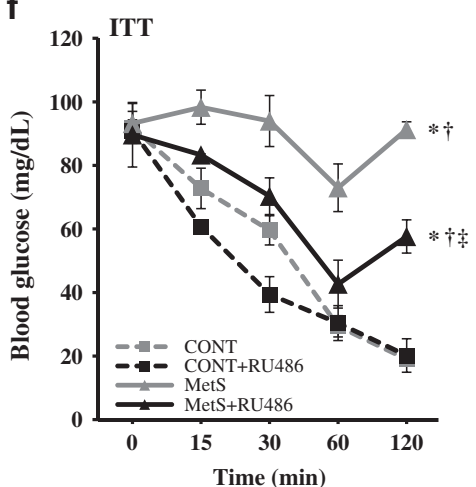

Figure 1 Time course of body weight (a), food intake (b), SBP (c) and heart rate (d), as well as the results of an OGTT (e) and ITT (f) performed at 13 weeks of age for rats in the four experimental groups. Data are expressed as means \pm s.e.m. $(n=9,11,10$ and 10 for CONT, CONT+RU486, MetS and MetS+RU486, respectively). ${ }^{*} P<0.05$ vs. CONT; ${ }^{\dagger} P<0.05$ vs. CONT+RU486; ${ }^{\ddagger} P<0.05$ vs. MetS. CONT, control; ITT, insulin tolerance test; MetS, metabolic syndrome; OGTT, oral glucose tolerance test; SBP, systolic blood pressure.

harboring a missense mutation in the leptin receptor gene (Lepr). When fed a normal diet, DS/obese rats develop a phenotype, including hypertension, similar to MetS in humans. They also develop cardiac abnormalities as well as fat-induced liver damage. ${ }^{17}$ The cardiac abnormalities include left ventricular (LV) diastolic dysfunction, as well as LV hypertrophy and fibrosis, and these changes are associated with increased cardiac oxidative stress and inflammation. ${ }^{18}$ Our recent results implicated the aldosterone-MR axis in hypertension and cardiac injury in DS/obese rats. ${ }^{19}$ We have now investigated the effects of the GR antagonist RU486 on cardiac and adipose tissue pathology and gene expression, as well as on glucose metabolism in DS/obese rats.

\section{METHODS}

\section{Animals and experimental protocols}

Male inbred DS/obese rats were injected subcutaneously with RU486 (2 mg per kg body weight per day; MetS+RU486 group) or vehicle (MetS group) from 9 weeks of age and were compared with homozygous lean (DahlS.Z-Lepr ${ }^{+} /$Lepr $^{+}$, or DS/lean) rats (CONT+RU486 and control (CONT) groups). Body weight as well as food and water intake were measured weekly. For an oral glucose tolerance test, glucose $\left(2 \mathrm{~g} \mathrm{~kg}^{-1}\right)$ was administered orally early in the morning to rats that had been deprived of food overnight. For an insulin tolerance test, human insulin $\left(0.75 \mathrm{U} \mathrm{kg}^{-1}\right.$; Eli Lilly Japan K.K., Kobe, Japan) was injected intraperitoneally in rats that had been deprived of food for $6 \mathrm{~h}$ beginning at 0900 hours. At 13 weeks of age, rats were anesthetized by intraperitoneal injection of ketamine $\left(50 \mathrm{mg} \mathrm{kg}^{-1}\right)$ and xylazine $\left(10 \mathrm{mg} \mathrm{kg}^{-1}\right)$ for echocardiographic and hemodynamic analyses. The animals were subsequently killed; the heart and both visceral (retroperitoneal and epididymal) and subcutaneous (inguinal) fat tissue were removed and weighed; and LV tissue was dissected from the heart for analysis. Further details are provided in the Supplementary Information.

\section{Echocardiographic and hemodynamic analyses}

Systolic blood pressure (SBP) and heart rate were measured weekly in conscious animals by tail-cuff plethysmography (BP-98A; Softron, Tokyo, Japan). At 13 weeks of age, rats were subjected to transthoracic echocardiography, as described previously. ${ }^{20}$ Further details are provided in the Supplementary Information.

\section{Other methods}

Measurement of metabolic and hormonal parameters, histology and immunohistochemistry, assay of superoxide production, reverse transcription and real-time PCR analysis and immunoblot analysis are described in the Supplementary Information.

\section{Statistical analysis}

Data are presented as means \pm s.e.m. Differences among groups of rats at 13 weeks of age were assessed by one-way factorial analysis of variance (ANOVA); if a significant difference was detected, intergroup comparisons were performed with Fisher's multiple-comparison test. The time courses of body weight, food intake, SBP and heart rate, as well as the oral glucose tolerance test and insulin tolerance test curves, were compared among groups by two-way repeated-measures ANOVA. The independent or interactive influence of rat genotype and RU486 treatment on various parameters in the four experimental groups was evaluated with two-way factorial ANOVA. A $P$-value of $<0.05$ was considered statistically significant.

\section{RESULTS}

\section{Physiological parameters}

Body weight, food intake and SBP were significantly higher, whereas heart rate was significantly lower, in the MetS group compared with 
Table 1 Physiological parameters for rats in the four experimental groups at 13 weeks of age

\begin{tabular}{|c|c|c|c|c|}
\hline Parameter & CONT & $C O N T+R U 486$ & MetS & $M e t S+R U 486$ \\
\hline Body weight (g) & $386.8 \pm 3.7$ & $365.9 \pm 6.7$ & $484.2 \pm 7.6^{* \dagger}$ & $476.6 \pm 9.4^{* \dagger}$ \\
\hline Tibial length (mm) & $37.9 \pm 0.3$ & $37.5 \pm 0.3$ & $34.0 \pm 0.3^{* \dagger}$ & $34.1 \pm 0.2^{* \dagger}$ \\
\hline Food intake (g per day) & $23.0 \pm 1.5$ & $22.5 \pm 0.6$ & $32.0 \pm 1.0^{* \dagger}$ & $31.6 \pm 1.4^{* \dagger}$ \\
\hline $\mathrm{SBP}(\mathrm{mm} \mathrm{Hg})$ & $153.3 \pm 1.6$ & $140.7 \pm 1.8$ & $212.8 \pm 6.6^{* \dagger}$ & $221.9 \pm 4.2^{* \dagger}$ \\
\hline Heart rate (beats $\min ^{-1}$ ) & $391.0 \pm 10.5$ & $396.8 \pm 6.0$ & $361.9 \pm 13.3^{* \dagger}$ & $368.3 \pm 8.8^{* \dagger}$ \\
\hline Heart weight/tibial length $\left(\mathrm{mg} \mathrm{mm}^{-1}\right)$ & $33.8 \pm 0.9$ & $32.0 \pm 0.9$ & $40.5 \pm 0.9 * \dagger$ & $39.8 \pm 0.9^{* \dagger}$ \\
\hline LV weight/tibial length $\left(\mathrm{mg} \mathrm{mm}^{-1}\right)$ & $23.5 \pm 0.8$ & $22.0 \pm 0.7$ & $29.8 \pm 0.4^{* \dagger}$ & $28.4 \pm 0.9^{* \dagger}$ \\
\hline Retroperitoneal fat weight/tibial length $\left(\mathrm{mg} \mathrm{mm}^{-1}\right)$ & $84.7 \pm 4.0$ & $71.75 \pm 2.7$ & $439.5 \pm 10.8^{* \dagger}$ & $405.0 \pm 18.4^{* \dagger \ddagger}$ \\
\hline Epididymal fat weight/tibial length $\left(\mathrm{mg} \mathrm{mm}^{-1}\right)$ & $105.0 \pm 4.5$ & $93.9 \pm 4.1$ & $344.1 \pm 4.1^{* \dagger}$ & $334.9 \pm 12.6^{* \dagger}$ \\
\hline Inguinal fat weight/tibial length $\left(\mathrm{mg} \mathrm{mm}^{-1}\right.$ ) & $121.8 \pm 7.8$ & $101.9 \pm 8.4$ & $624.2 \pm 29.0^{* \dagger}$ & $533.2 \pm 36.9^{* \dagger \ddagger}$ \\
\hline Cross-sectional area of visceral adipocytes $\left(\mu \mathrm{m}^{2}\right)$ & $2323.5 \pm 77.9$ & $2267.5 \pm 133.8$ & $11824.4 \pm 481.2^{* \dagger}$ & $8019.2 \pm 270.2^{* \dagger \ddagger}$ \\
\hline Fasting serum glucose $\left(\mathrm{mg} \mathrm{dl}^{-1}\right)$ & $112.8 \pm 2.9$ & $116.2 \pm 2.9$ & $162.0 \pm 8.3^{* \dagger}$ & $121.7 \pm 8.5 \ddagger$ \\
\hline Fasting plasma insulin ( $\mathrm{ng} \mathrm{ml}^{-1}$ ) & $0.44 \pm 0.09$ & $0.49 \pm 0.12$ & $6.31 \pm 0.47^{* \dagger}$ & $2.94 \pm 0.78^{* \dagger \ddagger}$ \\
\hline HOMA-IR & $3.1 \pm 0.8$ & $3.7 \pm 1.0$ & $73.3 \pm 6.9 * \dagger$ & $22.9 \pm 6.6^{* \dagger \ddagger}$ \\
\hline HOMA- $\beta$ & $85.1 \pm 19.3$ & $83.3 \pm 15.3$ & $673.5 \pm 48.7^{* \dagger}$ & $487.7 \pm 112.1^{* \dagger \ddagger}$ \\
\hline Plasma corticosterone (ng ml $\mathrm{ml}^{-1}$ ) & $276.6 \pm 54.1$ & $298.2 \pm 43.9$ & $299.4 \pm 23.4$ & $260.0 \pm 52.5$ \\
\hline Plasma aldosterone $\left(\mathrm{pg} \mathrm{ml}^{-1}\right)$ & $203.8 \pm 15.1$ & $326.0 \pm 48.5^{*}$ & $233.4 \pm 16.0^{\dagger}$ & $191.6 \pm 28.0^{\dagger}$ \\
\hline
\end{tabular}

Abbreviations: CONT, control; HOMA-IR, homeostasis model assessment of insulin resistance; HOMA- $\beta$, homeostasis model assessment of $\beta$-cell function; MetS, metabolic syndrome; SBP, systolic blood pressure.

${ }^{*} P<0.05$ vs. CONT; ${ }^{\dagger} P<0.05$ vs. CONT+RU486; ${ }^{\ddagger} P<0.05$ vs. MetS.

Data are means \pm s.e.m. ( $n=9,11,10$ and 10 for CONT, CONT+RU486, MetS and MetS+RU486 groups, respectively).

the CONT group, and RU486 did not affect any of these parameters in MetS or CONT rats (Figures 1a-d,Table 1). At 13 weeks of age, the ratios of heart or LV weight to tibial length (indices of cardiac and LV hypertrophy, respectively) were significantly increased in the MetS group compared with the CONT group, and treatment with RU486 did not significantly affect these changes (Table 1). The ratios of visceral (retroperitoneal or epididymal) or subcutaneous (inguinal) fat weight to tibial length were increased in the MetS group compared with the CONT group, and RU486 significantly reduced the ratios of retroperitoneal or subcutaneous fat weight to tibial length in MetS rats.

Both fasting serum glucose and plasma insulin concentrations were significantly higher in the MetS group than in the CONT group, and these changes were attenuated in the MetS+RU486 group (Table 1). Homeostasis model assessment of both insulin resistance (HOMA-IR) and $\beta$-cell function (HOMA- $\beta$ ) were also significantly increased in the MetS group, and RU486 attenuated these effects in MetS rats. Moreover, RU486 ameliorated the reduced glucose tolerance and the insulin resistance apparent in MetS rats (Figures 1e and f). The plasma concentration of corticosterone was similar in all four groups of rats (Table 1). There was no significant difference in plasma aldosterone concentration between the CONT and the MetS groups. RU486 significantly increased plasma aldosterone concentration in DS/lean rats but not in DS/obese rats.

Echocardiography revealed that the interventricular septum thickness, LV posterior wall thickness, LV fractional shortening, LV ejection fraction, LV mass and relative wall thickness were significantly increased in the MetS group compared with the CONT group (Supplementary Table 1). With the exception of relative wall thickness, these parameters were not affected by treatment of MetS rats with RU486. The ratio of the peak-flow velocity at the mitral level during rapid filling to that during atrial contraction ( $E / A$ ratio) was significantly reduced, whereas the deceleration time, isovolumic relaxation time and the time constant of isovolumic relaxation (tau), as well as the LV end-diastolic pressure and the ratio of LV enddiastolic pressure to the LV end-diastolic dimension, were increased in the MetS group compared with the CONT group. All of these changes were attenuated in the MetS+RU486 group. These data thus indicated that RU486 attenuated LV remodeling, preserved LV systolic function and ameliorated LV diastolic dysfunction in DS/obese rats.

\section{Cardiomyocyte hypertrophy as well as cardiac fibrosis and gene expression}

Microscopic analysis revealed that the cross-sectional area of cardiac myocytes was increased in the MetS group compared with the CONT group, and this effect was not influenced by the treatment with RU486 (Figures 2a and b). Hemodynamic overload resulted in marked upregulation of the expression of fetal-type cardiac genes, including those for atrial natriuretic peptide, brain natriuretic peptide and $\beta$-myosin heavy chain, in the MetS group, and these changes were also not substantially affected by RU486 (Figures 2c-e).

Azan-Mallory staining revealed that fibrosis in perivascular and interstitial regions of the LV myocardium was increased in the MetS group compared with the CONT group, and this effect was ameliorated by the treatment of MetS rats with RU486 (Figures $2 \mathrm{f}-\mathrm{i}$ ). The abundance of collagen types I and III mRNAs, as well as the amounts of connective tissue growth factor and transforming growth factor- $\beta 1$ mRNAs, were also increased in the MetS group in a manner sensitive to treatment with RU486 (Figures $2 \mathrm{j}-\mathrm{m}$ ).

\section{Cardiac oxidative stress}

Superoxide production in myocardial tissue sections, as revealed by staining with dihydroethidium, as well as the activity of reduced NADPH oxidase in homogenates of LV tissue were significantly increased in the MetS group compared with the CONT group (Figures 3a-c). Cardiac expression of genes for the p22 phox and gp91 phox membrane components and for the p67phox and Rac1 cytosolic components of NADPH oxidase was also upregulated in the MetS group (Figures 3d-g). RU486 treatment attenuated all of these effects in MetS rats.

\section{Cardiac inflammation}

Immunostaining for the monocyte-macrophage marker CD68 revealed that macrophage infiltration in the LV myocardium was 
a

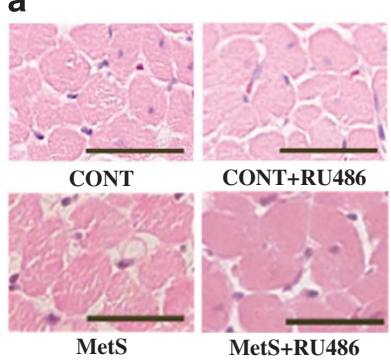

b

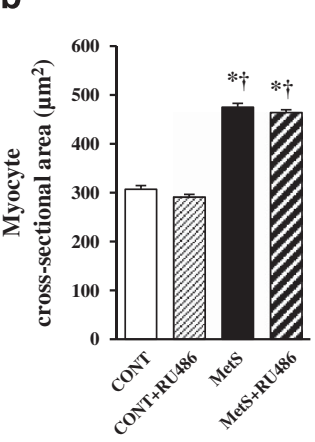

C

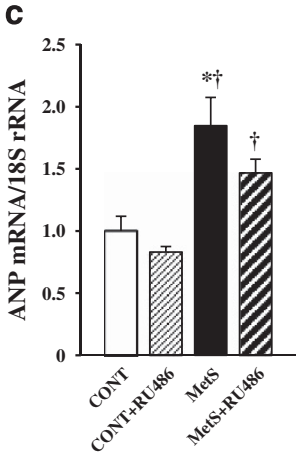

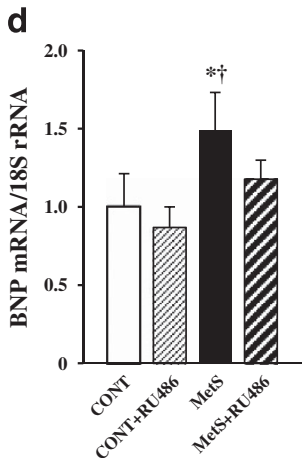

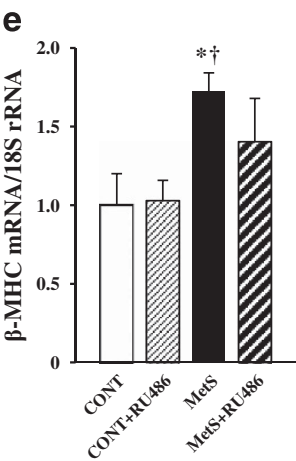

f

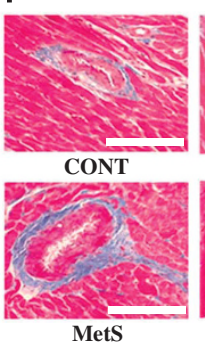

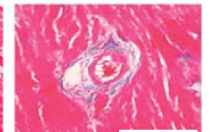

CONT+RU486

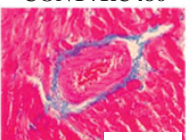

MetS+RU486 g

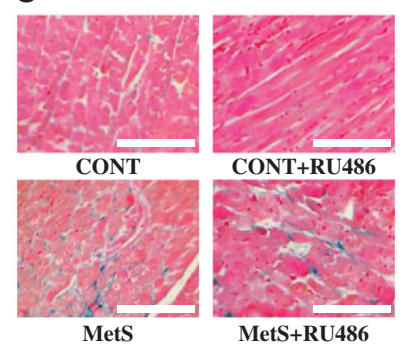

h

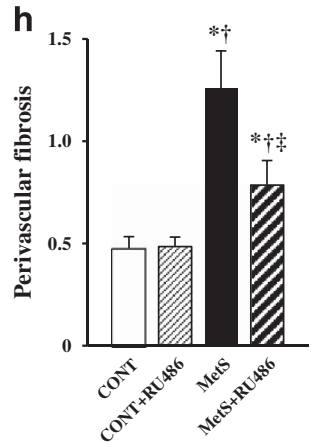

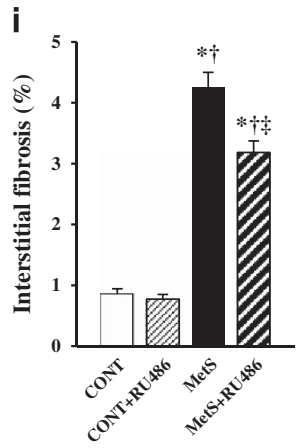

j

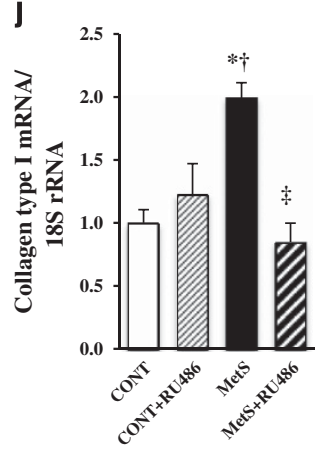

k

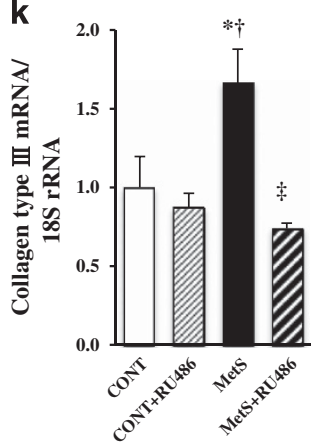

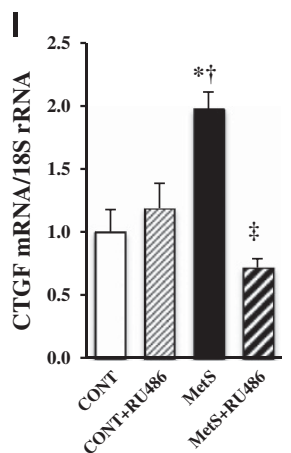

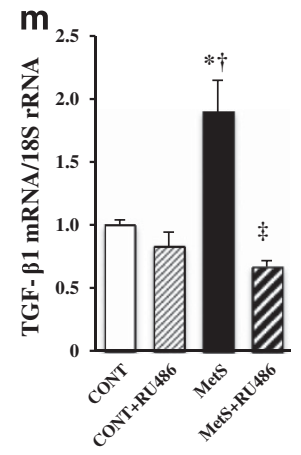

Figure 2 Cardiomyocyte size, expression of fetal-type cardiac genes, cardiac fibrosis and expression of fibrosis-related genes in the left ventricle of rats in the four experimental groups at 13 weeks of age. (a) Hematoxylin-eosin staining of transverse sections of the LV myocardium. Scale bars, $50 \mu \mathrm{m}$. (b) Crosssectional area of cardiac myocytes determined from sections similar to those in a. (c-e) Quantitative RT-PCR analysis of ANP, BNP and $\beta$-MHC mRNAs, respectively. The amount of each mRNA was normalized by that of $18 \mathrm{~S}$ rRNA and then expressed relative to the normalized value for the CONT group. $(\mathbf{f}, \mathbf{g})$ Collagen deposition as revealed by Azan-Mallory staining in perivascular and interstitial regions of the LV myocardium, respectively. Scale bars, $100 \mu \mathrm{m}$. (h, i) Relative extents of perivascular and interstitial fibrosis, respectively, as determined from sections similar to those in $\mathbf{f}$ and $\mathbf{g}$. (j-m) Quantitative RT-PCR analysis of collagen types I and III, CTGF and TGF- $\beta 1$ mRNAs, respectively. All data are expressed as means \pm s.e.m. for the indicated numbers of animals in Figure 1. ${ }^{*} P<0.05$ vs. CONT; ${ }^{\dagger} P<0.05$ vs. CONT+RU486; ${ }^{\ddagger} P<0.05$ vs. MetS. ANP, atrial natriuretic peptide; BNP, brain natriuretic peptide; CONT, control; CTGF, connective tissue growth factor; MetS, metabolic syndrome; rRNA, ribosomal RNA; RT-PCR, reverse transcriptase-PCR; SBP, systolic blood pressure; TGF- $\beta 1$, transforming growth factor- $\beta 1 ; \beta-\mathrm{MHC}, \beta$-myosin heavy chain.

increased in the MetS group compared with the CONT group, and RU486 inhibited such infiltration in MetS rats (Figures $3 \mathrm{~h}$ and i). Expression of the genes for monocyte chemoattractant protein-1 (MCP-1), osteopontin, cyclooxygenase-2 (COX-2) and tumor necrosis factor- $\alpha$ (TNF- $\alpha)$ in the left ventricle was also increased in the MetS group in a manner sensitive to RU486 treatment (Figures $3 \mathrm{j}-\mathrm{m}$ ).

\section{Cardiac renin-angiotensin-aldosterone system and} glucocorticoid-related gene expression

The amounts of angiotensin-converting enzyme, MR, serum/glucocorticoid-regulated kinase $1,11 \beta-\mathrm{HSD} 1$ and GR mRNAs in the left ventricle were increased in the MetS group compared with the CONT group, and these effects were attenuated in the MetS+RU486 group (Figures $4 \mathrm{a}-\mathrm{e}$ ). The amounts of $11 \beta-\mathrm{HSD} 1$ and GR proteins in the left ventricle showed a pattern similar to that for the corresponding mRNAs in the four experimental groups (Figures $4 \mathrm{f}$ and $\mathrm{g}$ ). There was no significant difference in the amount of 11 $\beta$-HSD2 mRNA in the heart between the CONT and MetS groups (Supplementary Figure 1). RU486 increased the expression of $11 \beta-H S D 2$ gene in the heart of the MetS group but not in that of the CONT group.

\section{Adipocyte hypertrophy as well as adipose tissue inflammation} and gene expression

Hematoxylin-eosin staining and immunostaining for the monocytemacrophage marker CD68 revealed that adipocyte cross-sectional area 
a

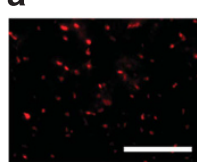

CONT

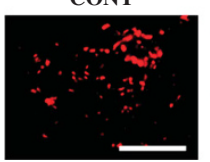

MetS

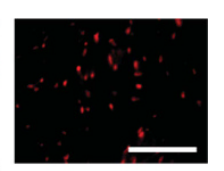

CONT+RU486

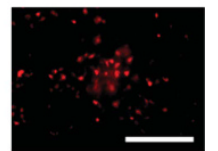

MetS+RU486

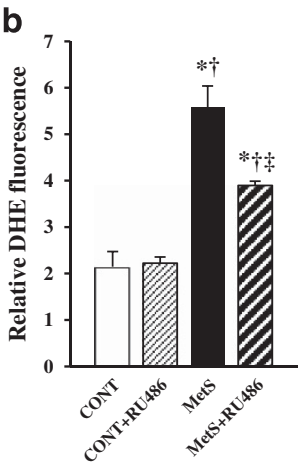

C

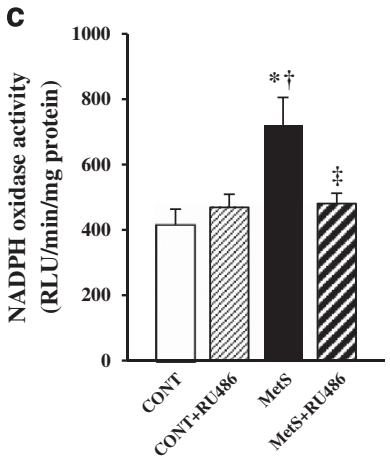

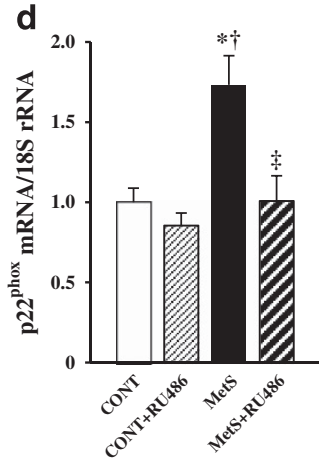

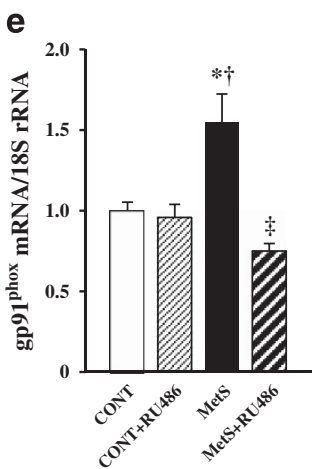

f

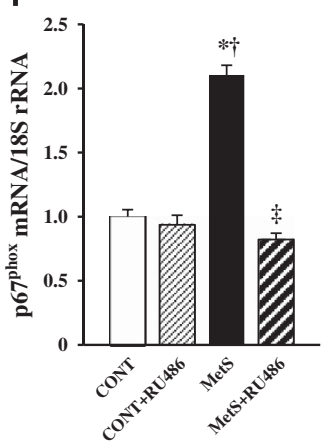

g

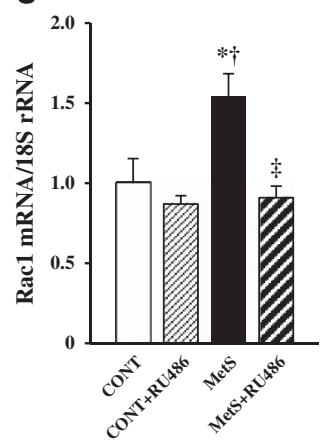

h

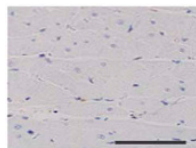

CONT

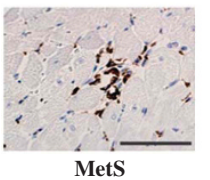

CONT+RU486

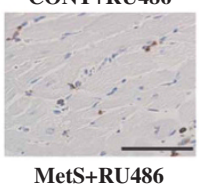

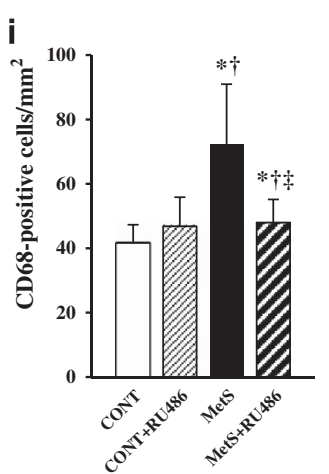

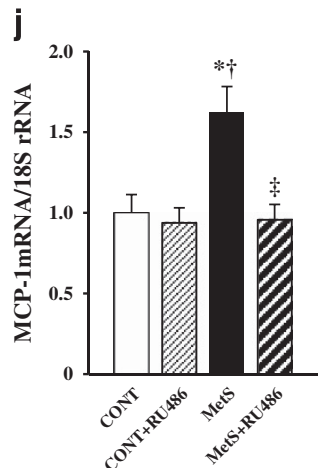

k
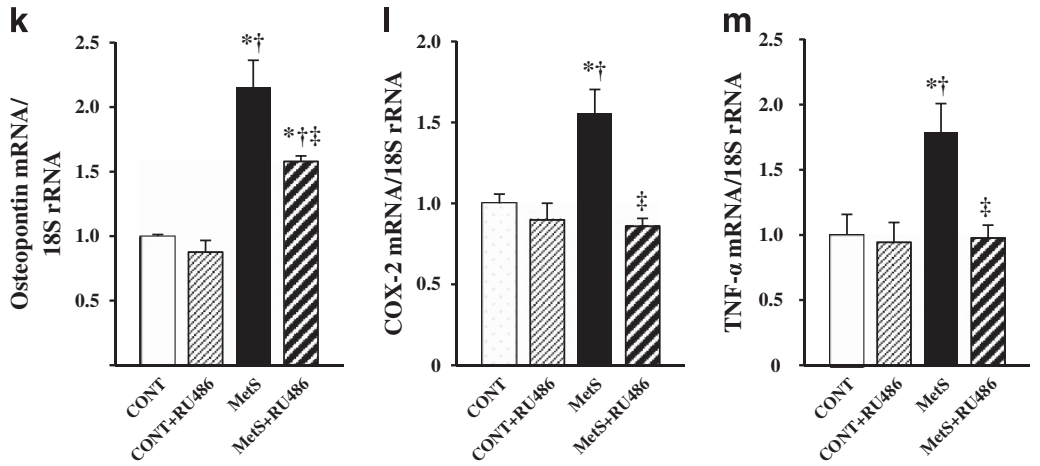

Figure $3 \mathrm{NADPH}$ oxidase activity and gene expression as well as macrophage infiltration and inflammatory gene expression in the left ventricle of rats in the four experimental groups at 13 weeks of age. (a) Superoxide production as revealed by dihydroethidium staining in interstitial regions of the LV myocardium. Scale bars, $100 \mu \mathrm{m}$. (b) Relative dihydroethidium (DHE) fluorescence intensity determined from sections similar to those in a. (c) NADPH-dependent superoxide production in LV tissue homogenates. Data are expressed as relative light units (RLU) per minute per milligram of protein. (d-g) Quantitative RT-PCR analysis of p22 ${ }^{\text {phox }}$, gp91 phox, p67 phox and Rac1 mRNAs, respectively. The amount of each mRNA was normalized by that of $18 \mathrm{~S}$ rRNA and then expressed relative to the normalized value for the CONT group. (h) Immunohistochemical analysis with antibodies to the monocyte-macrophage marker CD68. Scale bars, $50 \mu \mathrm{m}$. (i) Density of CD68-positive cells determined from sections similar to those in $\mathbf{h}$. (j-m) Quantitative RT-PCR analysis of MCP-1, osteopontin, COX-2 and TNF- $\alpha$ mRNAs, respectively. All data are expressed as means \pm s.e.m. for the indicated numbers of animals in Figure $1 .{ }^{*} P<0.05$ vs. CONT; ${ }^{\dagger} P<0.05$ vs. CONT+RU486; ${ }^{\ddagger} P<0.05$ vs. MetS. CONT, control; COX-2, cyclooxygenase-2; MCP-1, monocyte chemoattractant protein-1; MetS, metabolic syndrome; rRNA, ribosomal RNA; RT-PCR, reverse transcriptase-PCR; TNF- $\alpha$, tumor necrosis factor- $\alpha$.

and macrophage infiltration in visceral adipose tissue were increased in the MetS group compared with the CONT group, and these effects were attenuated by RU486 (Figures $5 \mathrm{a}$ and b; Table 1). The expression of $M C P-1, C O X-2$ and TNF- $\alpha$ genes in visceral adipose tissue was also increased in the MetS group, and these effects were attenuated in the MetS+RU486 group (Figures 5c-e). The amounts of $11 \beta$-hydroxylase, $11 \beta$-HSD 1 and GR mRNAs in adipose tissue were also increased in the MetS group in a manner sensitive to RU486 treatment (Figures $5 \mathrm{f}-\mathrm{h}$ ). The amounts of $11 \beta$-HSD1 and GR proteins in adipose tissue showed a pattern similar to that for the corresponding mRNAs in the four experimental groups (Figures 5i, j). The 11 $\beta$-HSD2 mRNA was expressed at only minimal levels in the adipose tissue of rats in the four experimental groups (data not shown).

\section{Influences of genotype and RU486 treatment}

We also analyzed all the data of the study by two-way factorial ANOVA in order to determine the influences of rat genotype and RU486 treatment and the possible interaction of these factors (data not shown). There were no interactions between strains and RU486 treatment in body weight, tibial length or food intake (data not shown). The interaction was significant in SBP, whereas there were no significant differences in heart rate, heart weight or LV weight. 

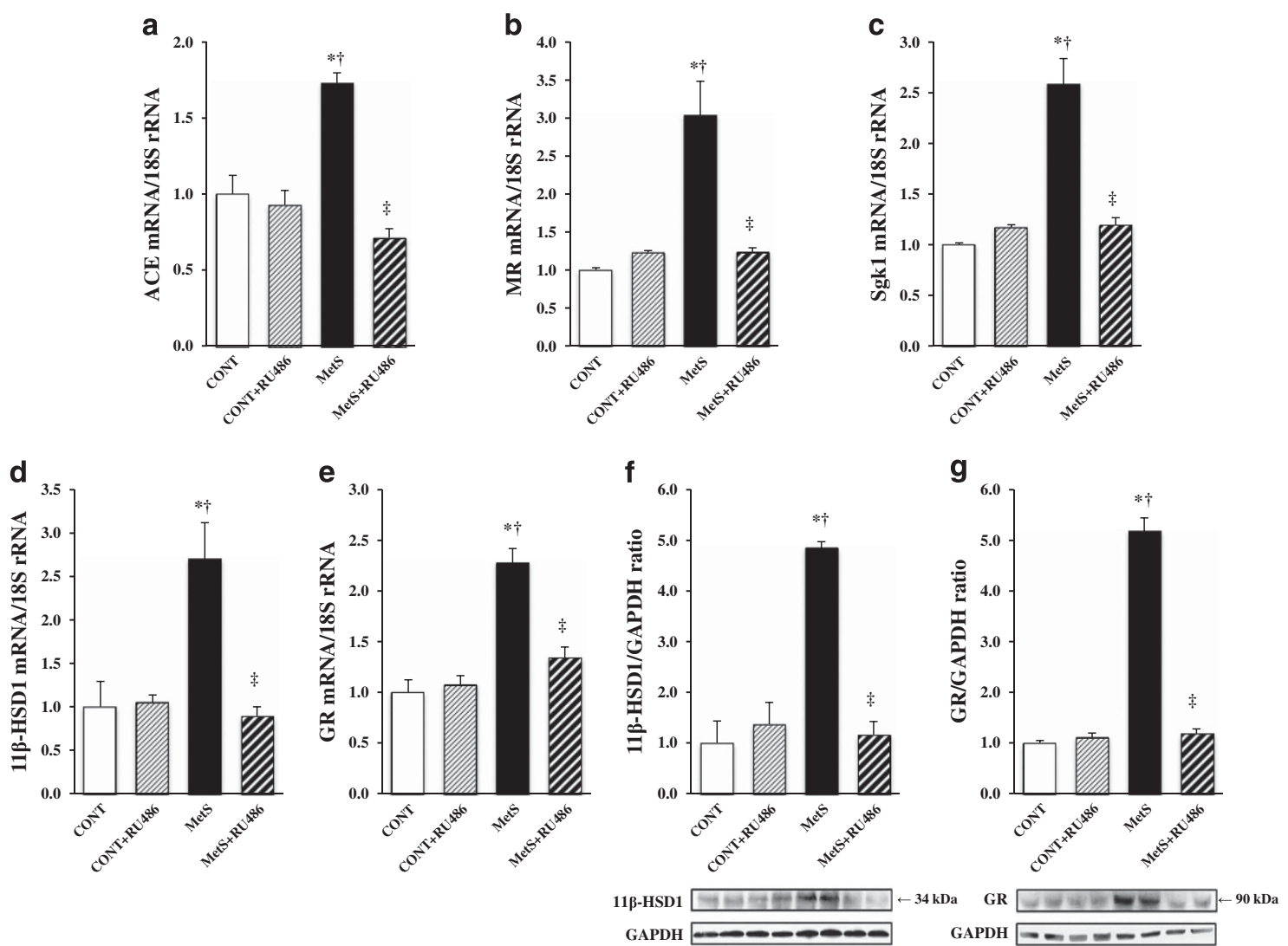

Figure 4 Cardiac RAAS and glucocorticoid-related gene expression in the left ventricle of rats in the four experimental groups at 13 weeks of age. (a-e) Quantitative RT-PCR analysis of ACE, MR, Sgk1, 11ß-HSD1 and GR mRNAs, respectively. The amount of each mRNA was normalized by that of $18 \mathrm{~S}$ rRNA and then expressed relative to the normalized value for the CONT group. (f, g) Immunoblot analysis of $11 \beta$-HSD1 and GR proteins, respectively. Representative immunoblots as well as the relative ratio of the amount of $11 \beta$-HSD1 or the GR to that of GAPDH are shown. All data are expressed as means \pm s.e.m. for the indicated numbers of animals in Figure $1 .{ }^{*} P<0.05$ vs. CONT; ${ }^{\dagger} P<0.05$ vs. CONT+RU486; ${ }^{\ddagger} P<0.05$ vs. MetS. ACE, angiotensinconverting enzyme; CONT, control; GR, glucocorticoid receptor; MetS, metabolic syndrome; MR, mineralocorticoid receptor; rRNA, ribosomal RNA; RT-PCR,

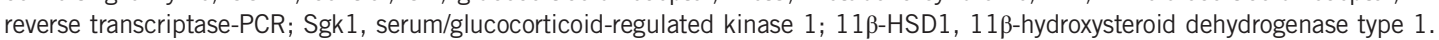

Although there were no interactions in adipose tissue weights (retroperitoneal, epididymal or inguinal fat), it was significant in cross-sectional area of visceral adipocytes. In glucose metabolism, they were significant in fasting serum glucose, fasting plasma insulin, HOMA-IR, oral glucose tolerance test and insulin tolerance test (except for HOMA- $\beta$ ). No significant interaction was detected in plasma corticosterone. With regard to echocardiographic and hemodynamic analyses, there were no interactions in LV dimensions (LV end-diastolic dimension and LV end-systolic dimension), wall thicknesses (interventricular septum thickness and LV posterior wall thickness), LV systolic function (LV fractional shortening and LV ejection fraction) or LV mass. The markers of cardiomyocyte hypertrophy (myocyte cross-sectional area, atrial natriuretic peptide, brain natriuretic peptide and $\beta$-myosin heavy chain) had no interaction. However, in relative wall thickness, E/A ratio, deceleration time, isovolumic relaxation time, Tei index, tau, LV end-diastolic pressure and LV end-diastolic pressure/LV end-diastolic dimension, the interactions were all significant. Significant interactions were observed in perivascular and interstitial fibrosis, and fibrosis-related genes (collagen I, connective tissue growth factor, and transforming growth factor- $\beta 1)$. There were significant interactions in cardiac oxidative stress (dihydroethidium staining, NADPH oxidase activity, p22 $2^{\text {phox }}$, gp91phox and Rac1), cardiac inflammation (CD68-positive cells, MCP-1, osteopontin and COX-2) and cardiac renin-angiotensin- aldosterone system (RAAS) (angiotensin-converting enzyme, MR and serum/glucocorticoid-regulated kinase 1) and glucocorticoid-related (11 $\beta$-HSD1 and GR) gene expressions. Finally, the interactions in adipose tissue inflammation (CD68-positive cells, MCP-1 and COX-2)

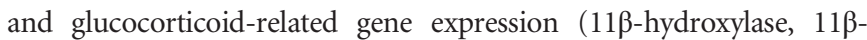
HSD1 and GR) were all significant. Thus, the data analyzed by twoway factorial ANOVA were compatible with the original results analyzed by 1-way factorial ANOVA.

\section{DISCUSSION}

We have here shown that the GR antagonist RU486 attenuated LV fibrosis and diastolic dysfunction as well as LV oxidative stress and inflammation, without lowering blood pressure, in DS/obese rats. In addition, treatment with RU486 ameliorated glucose intolerance and insulin resistance, reduced adiposity and adipose tissue inflammation, attenuated the upregulation of $11 \beta-H S D 1$ and GR mRNA and protein expression in adipose tissue and the heart. These findings suggest that activation of glucocorticoid-GR signaling may contribute to the pathophysiology of MetS and its associated complications.

The elevation of SBP in DS/obese rats was accompanied by increases in both HOMA-IR and cardiac inflammation, consistent with the notion that insulin resistance and inflammation may give rise to altered vascular function and thereby lead to hypertension. ${ }^{21,22}$ Although cortisol, the major glucocorticoid in humans, has many 
a
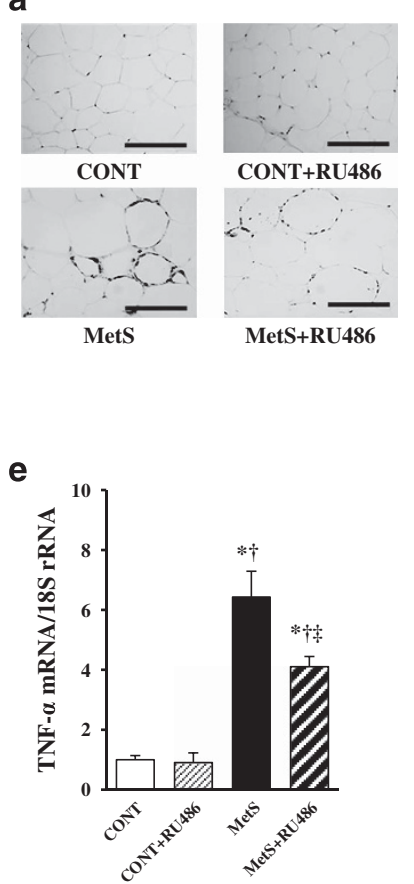

i

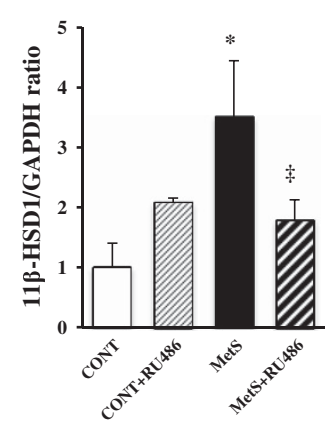

b

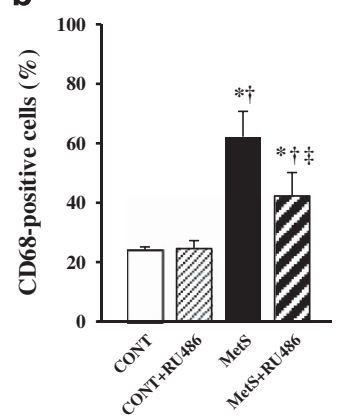

f

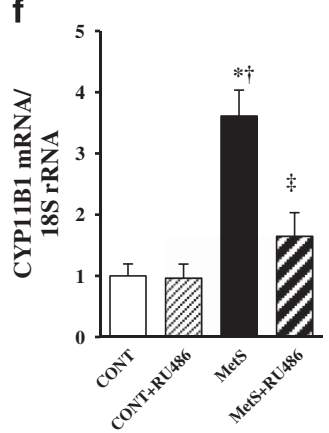

j

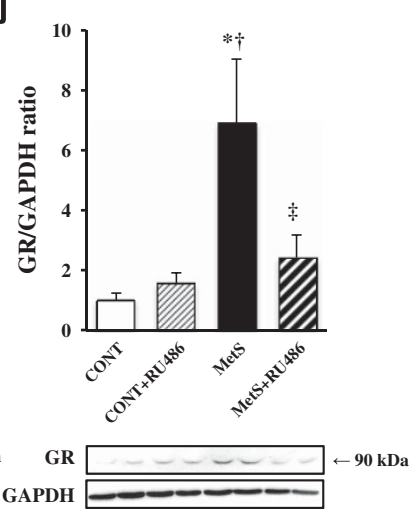
GAPDH
C

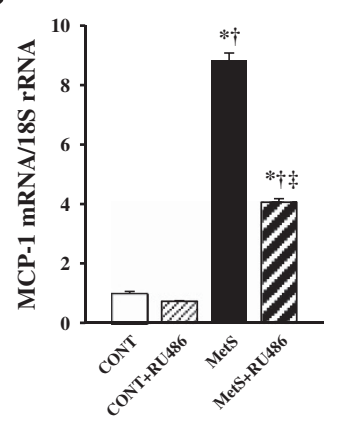

g

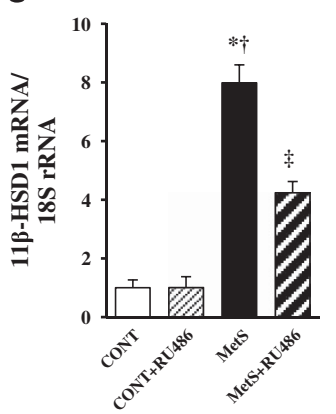

d

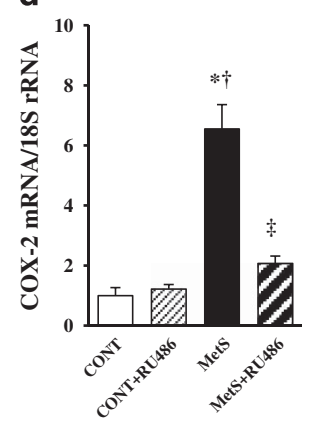

h

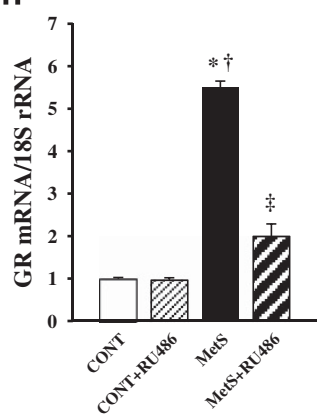

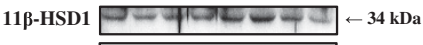
GAPDH

Figure 5 Macrophage infiltration as well as inflammatory and glucocorticoid-related gene expression in visceral (retroperitoneal) adipose tissue of rats in the four experimental groups at 13 weeks of age. (a) Immunohistochemical analysis with antibodies to the monocyte-macrophage marker CD68. Scale bars, $100 \mu \mathrm{m}$. (b) The number of nuclei for CD68-positive cells as a percentage of total nuclei was determined from sections similar to those in a. (c-h) Quantitative RT-PCR analysis of MCP-1, COX-2, TNF- $\alpha$, CYP11B1, 11 -HSD1 and GR mRNAs, respectively. The amount of each mRNA was normalized by that of $18 \mathrm{~S}$ rRNA and then expressed relative to the normalized value for the CONT group. (i, j) Immunoblot analysis of $11 \beta$-HSD1 and GR proteins, respectively. Representative immunoblots as well as the relative ratio of the amount of $11 \beta$-HSD1 or the GR to that of GAPDH are shown. All data are expressemeans \pm s.e.m. for the indicated numbers of animals in Figure $1 .{ }^{*} P<0.05$ vs. CONT; ${ }^{\dagger} P<0.05$ vs. CONT+RU486; ${ }^{\ddagger} P<0.05$ vs. MetS. CONT, control; COX-2, cyclooxygenase-2; CYP11B1, 11ß-hydroxylase; GR, glucocorticoid receptor; MCP-1, monocyte chemoattractant protein-1; MetS, metabolic syndrome; rRNA, ribosomal RNA; RT-PCR, reverse transcriptase-PCR; TNF- $\alpha$, tumor necrosis factor- $\alpha$; $11 \beta-H S D 1,11 \beta-$ hydroxysteroid dehydrogenase type 1.

effects on the brain, heart, blood vessels, kidney and body fluid compartments, the precise mechanism by which it increases blood pressure is unclear. ${ }^{23}$ Treatment with RU486 did not affect hypertension in DS/obese rats, suggesting that GRs may not contribute to the development of hypertension in these animals. These data are consistent with previous results showing that RU486 did not modify adrenocorticotropic hormone-induced hypertension despite demonstrable anti-glucocorticoid actions in rats. ${ }^{24}$ In contrast, other studies have shown that RU486 reduced both blood pressure ${ }^{25}$ and body weight. ${ }^{26}$ Such discrepancies might be due to differences in the dose of RU486 administered, which was smaller in the present study than in these latter two studies. ${ }^{26,27}$
Cardiac pathology associated with glucocorticoid excess may be secondary to the adverse systemic effects of these steroids, such as the development of hypertension and MetS. RU486 did not affect cardiac hypertrophy or upregulation of the expression of fetal-type cardiac genes including those for atrial natriuretic peptide, brain natriuretic peptide and $\beta$-myosin heavy chain in the heart of DS/obese rats. Direct activation of GR signaling in cardiomyocytes may negatively affect cardiac function by promoting pathological cardiac hypertrophy. ${ }^{3,27}$ In contrast, genetically engineered mice that overexpress GR specifically in cardiomyocytes do not develop spontaneous cardiac hypertrophy, but they do manifest conduction defects such as atrioventricular block. ${ }^{28}$ Cardiac fibrosis is a pathological feature associated with 
hypertension and gives rise to LV diastolic dysfunction, likely as a result of increased LV diastolic stiffness. ${ }^{29}$ RU486 ameliorated LV fibrosis and diastolic stiffness as well as attenuated LV oxidative stress and inflammation, without lowering blood pressure, in DS/obese rats, implicating GRs in the development of cardiac fibrosis and diastolic dysfunction in these animals. These data suggest that glucocorticoid effects are mediated via both MRs and GRs in the heart. ${ }^{30}$ They are also consistent with evidence that cardiomyocyte hypertrophy is primarily load dependent, whereas cardiac fibrosis is mostly load independent. ${ }^{31}$ Although RU486 does not bind to the MR or the estrogen receptor, it antagonizes the progesterone receptor to reduce MR expression and transcriptional activity. ${ }^{32}$ Thus, the blockade of progesterone receptors might explain in part the anti-fibrotic effect of RU486 observed in the heart of DS/obese rats, even though they are male rats.

Macrophages have been implicated in fibrosis associated with various pathological conditions. We recently showed that macrophage infiltration into the interstitial space of the LV myocardium was accompanied by increased expression of genes for proinflammatory proteins such as MCP-1 and TNF- $\alpha$ in the heart of DS/obese rats, ${ }^{18}$ consistent with previous observations showing the upregulation of proinflammatory factors in obese humans. ${ }^{33}$ These changes may thus contribute to the development of myocardial fibrosis in DS/obese rats. ${ }^{34,35}$ RU486 attenuated macrophage infiltration into the myocardium as well as the upregulation of MCP-1, osteopontin, COX-2 and TNF- $\alpha$ gene expression in the heart of DS/obese rats, indicating that RU486 alleviated cardiac inflammation in these animals. These results also support the previous finding that GRs are present in inflammatory cells, including macrophages, that invade vascular lesions. ${ }^{36}$ Increased oxidative stress has been recognized in experimental animal and human obesity and may contribute to the development of MetS. ${ }^{37}$ We found that RU486 attenuated increases in both the NADPH-dependent generation of superoxide and the expression of $\mathrm{NADPH}$ oxidase subunit genes in the heart of DS/obese rats, indicating that GR blockade reduced cardiac oxidative stress.

The RAAS has also been implicated in the pathogenesis of MetS. ${ }^{38}$ Our recent data suggest that relative aldosterone excess and activation of the cardiac RAAS may contribute to cardiac remodeling and diastolic dysfunction in DS/obese rats. ${ }^{18}$ We have also found that both increased oxidative stress and MR activation in the heart may promote LV remodeling and diastolic dysfunction in DS/obese rats, ${ }^{19}$ consistent with a causative role for RAAS activation in the development of cardiac injury associated with MetS. ${ }^{39}$ In the present study, RU486 attenuated the upregulation of mRNAs for angiotensinconverting enzyme, the MR and the aldosterone effector kinase serum/glucocorticoid-regulated kinase 1 in the heart of DS/obese rats, indicating that GR signaling may contribute to activation of the cardiac RAAS. We also confirmed that there was no significant difference in plasma aldosterone concentration between the CONT and MetS groups. ${ }^{18,19}$ RU486 increased plasma aldosterone levels in DS/lean rats but not in DS/obese rats. These results are somewhat similar to those of a previous study with Zucker rats showing that RU486 significantly reduced plasma aldosterone concentration in obese rats but not in lean rats. ${ }^{40}$ These findings also suggest that RAAS in the adrenal glands or adipose tissue might be regulated by GRs. RU486 also attenuated the increased expression of the GR and $11 \beta$-HSD1 apparent at the mRNA and protein levels in the heart of DS/obese rats, suggesting that cardiac glucocorticoid activity may promote LV remodeling and diastolic dysfunction in these animals. Expression of $11 \beta$-HSD 2 gene in the heart was similar in the CONT and the MetS group and RU486 increased the expression of $11 \beta$-HSD2 gene in the heart of the MetS group but not in that of the CONT group. Thus, in the heart of DS/obese rats, GRs could be involved in the control of local glucocorticoid levels by coordinately regulating both $11 \beta$-HSD1 and $11 \beta$-HSD2 gene expression. Together, these findings suggest that, in addition to MRs, GRs may also contribute to the pathogenesis of LV remodeling and diastolic dysfunction in DS/obese rats. As insulin resistance (HOMA-IR) was not affected by eplerenone, ${ }^{19}$ the pathophysiology of MetS per se may be primarily dependent on the glucocorticoid-GR axis.

Glucocorticoids promote the differentiation of pre-adipocytes into mature adipocytes and regulate adipose tissue distribution and function, and they are, therefore, associated with the accumulation of body fat. ${ }^{41,42}$ RU486 reduced visceral (retroperitoneal) and subcutaneous fat mass in DS/obese rats. It also attenuated adipocyte hypertrophy as well as macrophage infiltration and the upregulation of MCP-1, COX- 2 and TNF- $\alpha$ gene expression in visceral adipose tissue of these animals. Moreover, RU486 prevented the increase in the amount of $11 \beta$-hydroxylase (the enzyme responsible for the final step of corticosterone biosynthesis) mRNA, as well as the upregulation of $11 \beta-H S D 1$ and the GR mRNA and protein expression in visceral adipose tissue of DS/obese rats. These results suggest that RU486 might inhibit both adiposity and adipose tissue inflammation in DS/obese rats by reducing glucocorticoid activity, leading to amelioration of insulin resistance and other beneficial changes in various features of MetS. Our findings are also consistent with previous results showing that central or truncal obesity is linked to insulin resistance ${ }^{7}$ and that adipose tissue-specific amplification of glucocorticoid signaling induces all the characteristic features of MetS. ${ }^{43-45}$ Activation of GRs in adipocytes results in increased expression of lipoprotein lipase $(L P L)$ gene and enhances triglyceride storage. Our data are consistent with previous results showing that visceral adipocytes express higher numbers of GRs and exhibit the expected increase in LPL responsiveness to glucocorticoids and that $11 \beta$-HSD1 activity is very high in visceral adipose tissue. ${ }^{45}$ Thus, the visceral fat depot is likely to contribute strongly to the production of high local concentrations of glucocorticoids.

Glucocorticoids clearly possess immunosuppressive actions. In fact, anti-inflammatory genes including interleukin-10, whose deletion in mice results in increased susceptibility to inflammatory disease, ${ }^{46}$ are markedly increased by glucocorticoids. Contrary to popular belief, however, the present results showed that blockade of GRs with RU486 attenuated inflammatory responses in adipose tissue and the heart, suggesting that activation of GR signaling can induce inflammation. In support of this notion, at the gene cluster level, a previous report showed a bidirectional action of glucocorticoids, which are both immunostimulatory and immunosuppressive at the same time even for the inflammation cluster. ${ }^{47}$ In addition, at the single gene level, there was an opposite regulation of molecules implicated in the inflammatory and immune responses by glucocorticoids, depending on the state of cellular activation. This effect may underscore that the GR signaling may be mediated by a different set of transcription factors, coactivators and corepressors, allowing a switch in promoter activity depending on the cellular activation status. ${ }^{48}$ Our results are also consistent with the notion that, in general, glucocorticoids are immunostimulatory within the normal physiologic range of hypothalamus-pituitary-adrenal axis activity and immunoinhibitory when glucocorticoid levels are increased, as in chronically stressed animals. ${ }^{49}$

In contrast, there are reports that MRs are chronically occupied by glucocorticoids ${ }^{50}$ and MR activation may have a crucial role in corticosteroid-induced adipogenesis. ${ }^{51}$ In the presence of GR 
knockdown as well as in GR knockout adipocytes, corticosterone increased the expression of genes for proinflammatory cytokines (MCP-1). Whereas GR knockout adipocytes displayed a mildly impaired adipogenesis during early differentiation, MR knockout cells completely failed to accumulate lipids. ${ }^{52}$ Moreover, MR, but not GR, knockdown inhibited glucocorticoid-induced adipose conversion of 3T3-L1 cells. ${ }^{51}$ Progesterone stimulates food intake and promotes fat deposition and indeed RU486 appears to be more sensitive in female than in male obese rats. ${ }^{53}$ On the other hand, the similarity between the effects of RU486 and adrenalectomy on obesity in Zucker fatty rats and in dietary models, suggests that it is the GR rather than the progesterone receptor that regulates the development of obesity. ${ }^{40}$ Nevertheless, we cannot rule out the possibility that inhibition of the progesterone receptor/MR axis may have been partly responsible for the beneficial effects of RU486 on glucose metabolism and inflammatory responses in the adipose tissue. RU486 is also an antagonist of androgen receptors. ${ }^{40}$ Evidence suggests that androgen deficiency in males and androgen excess in females produce metabolic dysfunction via deficient or excessive action of androgen receptors, respectively, in multiple tissues. ${ }^{54}$ Although both male and female DS/obese rats are infertile, it is possible that blockade of androgen receptors with RU486 may have affected glucose and energy metabolism in our rats.

Our observation that the plasma corticosterone concentration was not affected by RU486 in DS/obese or DS/lean rats appears inconsistent with previous results showing that GR blockade with RU486 increased serum corticosterone levels in rats. ${ }^{26,53}$ Again, this discrepancy might be due to the smaller dose of RU486 administered in our study than in these previous studies. However, another study in which RU486 was administered to rats at a dose higher than that used in our study also found a lack of effect on plasma corticosterone concentration. ${ }^{40}$ As the present study did not compare the effects of GR and/or MR blockade, we cannot determine the relative contribution of each receptor to the pathophysiology of MetS and its associated complications. However, we speculate that glucocorticoid-GR axis, together with aldosterone-MR and glucocorticoid-MR axes, may be intricately involved in adipose tissue dysfunction and cardiac injury associated with MetS.

In conclusion, the GR antagonist RU486 attenuated LV fibrosis and diastolic dysfunction as well as LV oxidative stress and inflammation, without lowering blood pressure, in DS/obese rats, an animal model of MetS. In addition, RU486 improved systemic glucose metabolism, ameliorated adipose tissue pathology, attenuated the upregulation of $11 \beta$-HSD1 and GR mRNA and protein expression in both adipose tissue and the heart. Activation of glucocorticoid-GR signaling may thus contribute to the pathophysiology of MetS and its associated complications, and GR blockade may therefore be effective for the treatment of MetS. The regulatory events leading to aberrant glucocorticoid-GR activity under conditions of insulin resistance or Type 2 diabetes are less clear. Further investigations are required to clarify the role of GRs and MRs in the pathogenesis of MetS and its associated cardiovascular complications.

\section{CONFLICT OF INTEREST}

The authors declare no conflict of interest.

\section{ACKNOWLEDGEMENTS}

We thank Dr Hiromi Ito and Sae Ohura for technical assistance. This work was supported by a grant from the Ministry of Education, Culture, Sports, Science, and Technology of Japan (no. 24590690 to KN).
1 Cole TJ. Glucocorticoid action and the development of selective glucocorticoid receptor ligands. Biotechnol Annu Rev 2006; 12: 269-300.

2 Muiesan ML, Lupia M, Salvetti M, Grigoletto C, Sonino N, Boscaro M, Rosei EA, Mantero F, Fallo $\mathrm{F}$. Left ventricular structural and functional characteristics in Cushing's syndrome. J Am Coll Cardiol 2003; 41: 2275-2279.

3 Whitehurst RM Jr, Zhang M, Bhattacharjee A, Li M. Dexamethasone-induced hypertrophy in rat neonatal cardiac myocytes involves an elevated L-type $\mathrm{Ca}^{2+}$ current. J Mol Cell Cardiol 1999; 31: 1551-1558.

4 Guder G, Bauersachs J, Frantz S, Weismann D, Allolio B, Ertl G, Angermann CE, Stork S. Complementary and incremental mortality risk prediction by cortisol and aldosterone in chronic heart failure. Circulation 2007; 115: 1754-1761.

5 Ren R, Oakley RH, Cruz-Topete D, Cidlowski JA. Dual role for glucocorticoids in cardiomyocyte hypertrophy and apoptosis. Endocrinology 2012; 153: 5346-5360.

6 Rose AJ, Herzig S. Metabolic control through glucocorticoid hormones: an update. Mol Cell Endocrinol 2013; 380: 65-78.

7 Rose AJ, Vegiopoulos A, Herzig S. Role of glucocorticoids and the glucocorticoid receptor in metabolism: insights from genetic manipulations. J Steroid Biochem $\mathrm{Mol}$ Biol 2010; 122: 10-20.

8 Seckl JR, Walker BR. Minireview: 11beta-hydroxysteroid dehydrogenase type 1-a tissue-specific amplifier of glucocorticoid action. Endocrinology 2001; 142: 1371-1376.

9 Tomlinson JW, Walker EA, Bujalska IJ, Draper N, Lavery GG, Cooper MS, Hewison M, Stewart PM. 11beta-hydroxysteroid dehydrogenase type 1: a tissue-specific regulator of glucocorticoid response. Endocr Rev 2004; 25: 831-866.

10 Staab CA, Maser E. 11beta-Hydroxysteroid dehydrogenase type 1 is an important regulator at the interface of obesity and inflammation. J Steroid Biochem $\mathrm{Mol}$ Biol 2010; 119: 56-72.

11 Evans RM. The steroid and thyroid hormone receptor superfamily. Science 1988; 240: 889-895.

12 Czerwinski-Helms SM, Hickson RC. Specificity of activated glucocorticoid receptor expression in heart and skeletal muscle types. Biochem Biophys Res Commun 1987; 142: 322-328.

13 Kayes-Wandover KM, White PC. Steroidogenic enzyme gene expression in the human heart. J Clin Endocrinol Metab 2000; 85: 2519-2525.

14 Gaeggeler HP, Gonzalez-Rodriguez E, Jaeger NF, Loffing-Cueni D, Norregaard R, Loffing J, Horisberger JD, Rossier BC. Mineralocorticoid versus glucocorticoid receptor occupancy mediating aldosterone-stimulated sodium transport in a novel renal cell line. J Am Soc Nephrol 2005; 16: 878-891.

15 Funder JW. Reconsidering the roles of the mineralocorticoid receptor. Hypertension 2009; 53: 286-290.

16 Ohtake M, Hattori T, Murase T, Takahashi K, Takatsu M, Ohtake M, Miyachi M, Watanabe S, Cheng XW, Murohara T, Nagata K. Glucocorticoids activate cardiac mineralocorticoid receptors in adrenalectomized Dahl salt-sensitive rats. Nagoya J Med Sci 2014; 76: 59-72.

17 Hattori T, Murase T, Ohtake M, Inoue T, Tsukamoto H, Takatsu M, Kato Y, Hashimoto K, Murohara T, Nagata K. Characterization of a new animal model of metabolic syndrome: the DahlS.Z-Leprfa/Leprfa rat. Nutr Diabetes 2011; 1: e1.

18 Murase T, Hattori T, Ohtake M, Abe M, Amakusa Y, Takatsu M, Murohara T, Nagata K. Cardiac remodeling and diastolic dysfunction in DahIS.Z-Lepr fa/Lepr fa rats: a new animal model of metabolic syndrome. Hypertens Res 2012; 35: 186-193.

19 Takahashi K, Takatsu M, Matsuura N, Nagasawa K, Hattori T, Watanabe S, Murohara T, Nagata K. Roles of oxidative stress and the mineralocorticoid receptor in cardiac pathology in a rat model of metabolic syndrome. Nagoya J Med Sci 2015; 77: 275-289.

20 Nagata K, Somura F, Obata K, Odashima M, Izawa H, Ichihara S, Nagasaka T, Iwase M, Yamada Y, Nakashima N, Yokota M. AT1 receptor blockade reduces cardiac calcineurin activity in hypertensive rats. Hypertension 2002; 40: 168-174.

21 Kotsis V, Stabouli S, Papakatsika S, Rizos Z, Parati G. Mechanisms of obesity-induced hypertension. Hypertens Res 2010; 33: 386-393.

22 Nakagami H, Pang Z, Shimosato T, Moritani T, Kurinami H, Koriyama H, Tenma A, Shimamura M, Morishita R. The dipeptidyl peptidase-4 inhibitor teneligliptin improved endothelial dysfunction and insulin resistance in the SHR/NDmcr-cp rat model of metabolic syndrome. Hypertens Res 2014; 37: 629-635.

23 Whitworth JA, Mangos GJ, Kelly JJ. Cushing, cortisol, and cardiovascular disease. Hypertension 2000; 36: 912-916.

$24 \mathrm{Li} \mathrm{M}$, Wen C, Fraser T, Whitworth JA. Adrenocorticotrophin-induced hypertension: effects of mineralocorticoid and glucocorticoid receptor antagonism. J Hypertens 1999; 17: 419-426.

25 Rickard AJ, Funder JW, Fuller PJ, Young MJ. The role of the glucocorticoid receptor in mineralocorticoid/salt-mediated cardiac fibrosis. Endocrinology 2006; 147: 5901-5906.

26 Langley SC, York DA. Effects of antiglucocorticoid RU486 on development of obesity in obese fa/fa Zucker rats. Am J Physiol 1990; 259: R539-R544.

27 Lister K, Autelitano DJ, Jenkins A, Hannan RD, Sheppard KE. Cross talk between corticosteroids and alpha-adrenergic signalling augments cardiomyocyte hypertrophy: a possible role for SGK1. Cardiovasc Res 2006; 70: 555-565.

28 Sainte-Marie Y, Nguyen Dinh Cat A, Perrier R, Mangin L, Soukaseum C, Peuchmaur M, Tronche F, Farman N, Escoubet B, Benitah JP, Jaisser F. Conditional glucocorticoid receptor expression in the heart induces atrio-ventricular block. FASEB J 2007; 21: 3133-3141. 
29 Nagata K, Obata K, Xu J, Ichihara S, Noda A, Kimata H, Kato T, Izawa H, Murohara T, Yokota M. Mineralocorticoid receptor antagonism attenuates cardiac hypertrophy and failure in low-aldosterone hypertensive rats. Hypertension 2006; 47: 656-664.

30 Sheppard KE, Autelitano DJ. 11 Beta-hydroxysteroid dehydrogenase 1 transforms 11-dehydrocorticosterone into transcriptionally active glucocorticoid in neonatal rat heart. Endocrinology 2002; 143: 198-204.

31 Yamada T, Nagata K, Cheng XW, Obata K, Saka M, Miyachi M, Naruse K, Nishizawa T, Noda A, Izawa H, Kuzuya M, Okumura K, Murohara T, Yokota M. Long-term administration of nifedipine attenuates cardiac remodeling and diastolic heart failure in hypertensive rats. Eur J Pharmacol 2009; 615: 163-170.

32 McDonnell DP, Shahbaz MM, Vegeto E, Goldman ME. The human progesterone receptor A-form functions as a transcriptional modulator of mineralocorticoid receptor transcriptional activity. J Steroid Biochem Mol Biol 1994; 48: 425-432.

33 Hotamisligil GS, Arner P, Caro JF, Atkinson RL, Spiegelman BM. Increased adipose tissue expression of tumor necrosis factor-alpha in human obesity and insulin resistance. J Clin Invest 1995; 95: 2409-2415.

34 Kuwahara F, Kai H, Tokuda K, Takeya M, Takeshita A, Egashira K, Imaizumi T. Hypertensive myocardial fibrosis and diastolic dysfunction: another model of inflammation? Hypertension 2004; 43: 739-745.

35 Paneni F, Gregori M, Tocci G, Palano F, Ciavarella GM, Pignatelli G, Marra A, Sciarretta S, Ferrucci A, Volpe M. Do diabetes, metabolic syndrome or their association equally affect biventricular function? A tissue Doppler study. Hypertens Res 2013; 36 36-42.

36 Walker BR. Glucocorticoids and cardiovascular disease. Eur J Endocrinol 2007; 157 545-559.

37 Furukawa S, Fujita T, Shimabukuro M, Iwaki M, Yamada Y, Nakajima Y, Nakayama O, Makishima M, Matsuda M, Shimomura I. Increased oxidative stress in obesity and its impact on metabolic syndrome. J Clin Invest 2004; 114: 1752-1761.

38 Boustany CM, Bharadwaj K, Daugherty A, Brown DR, Randall DC, Cassis LA Activation of the systemic and adipose renin-angiotensin system in rats with dietinduced obesity and hypertension. Am J Physiol Regul Integr Comp Physiol 2004; 287 R943-R949.

39 Matsui H, Ando K, Kawarazaki H, Nagae A, Fujita M, Shimosawa T, Nagase M, Fujita T. Salt excess causes left ventricular diastolic dysfunction in rats with metabolic disorder Hypertension 2008; 52: 287-294.

40 Clapham JC, Turner NC. Effects of the glucocorticoid II receptor antagonist mifepristone on hypertension in the obese Zucker rat. J Pharmacol Exp Ther 1997; 282 1503-1508.
41 Marin P, Darin N, Amemiya T, Andersson B, Jern S, Bjorntorp P. Cortisol secretion in relation to body fat distribution in obese premenopausal women. Metabolism 1992; 41 882-886.

42 Hauner H, Entenmann G, Wabitsch M, Gaillard D, Ailhaud G, Negrel R, Pfeiffer EF. Promoting effect of glucocorticoids on the differentiation of human adipocyte precursor cells cultured in a chemically defined medium. J Clin Invest 1989; 84: 1663-1670.

43 Masuzaki H, Paterson J, Shinyama H, Morton NM, Mullins JJ, SeckI JR, Flier JS A transgenic model of visceral obesity and the metabolic syndrome. Science 2001 294: 2166-2170.

44 Masuzaki H, Yamamoto H, Kenyon CJ, Elmquist JK, Morton NM, Paterson JM, Shinyama H, Sharp MG, Fleming S, Mullins JJ, Seckl JR, Flier JS. Transgenic amplification of glucocorticoid action in adipose tissue causes high blood pressure in mice. J Clin Invest 2003; 112: 83-90.

45 Montague CT, O'Rahilly S. The perils of portliness: causes and consequences of visceral adiposity. Diabetes 2000; 49: 883-888.

46 Kuhn R, Lohler J, Rennick D, Rajewsky K, Muller W. Interleukin-10-deficient mice develop chronic enterocolitis. Cell 1993; 75: 263-274.

47 Wilckens T, De Rijk R. Glucocorticoids and immune function: unknown dimensions and new frontiers. Immunol Today 1997; 18: 418-424.

48 McKenna NJ, Lanz RB, O'Malley BW. Nuclear receptor coregulators: cellular and molecular biology. Endocr Rev 1999; 20: 321-344.

49 Vandevyver S, Dejager L, Tuckermann J, Libert C. New insights into the antiinflammatory mechanisms of glucocorticoids: an emerging role for glucocorticoidreceptor-mediated transactivation. Endocrinology 2013; 154: 993-1007.

50 Funder JW. Mineralocorticoid receptors: distribution and activation. Heart Fail Rev 2005; 10: 15-22.

51 Caprio M, Feve B, Claes A, Viengchareun S, Lombes M, Zennaro MC. Pivotal role of the mineralocorticoid receptor in corticosteroid-induced adipogenesis. FASEB J 2007; 21: 2185-2194.

52 Hoppmann J, Perwitz N, Meier B, Fasshauer M, Hadaschik D, Lehnert H, Klein J. The balance between gluco- and mineralo-corticoid action critically determines inflammatory adipocyte responses. J Endocrinol 2010; 204: 153-164.

53 Okada S, York DA, Bray GA. Mifepristone (RU486), a blocker of type II glucocorticoid and progestin receptors, reverses a dietary form of obesity. Am J Physiol 1992; 262: R1106-R1110.

54 Navarro G, Allard C, Xu W, Mauvais-Jarvis F. The role of androgens in metabolism, obesity, and diabetes in males and females. Obesity (Silver Spring) 2015; 23 713-719.

Supplementary Information accompanies the paper on Hypertension Research website (http://www.nature.com/hr) 